\title{
Segmentation of the Electrocardiography Images as a Tool to Identify Heart Diseases
}

\author{
Latifah Listyalina*1, Dhimas Arief Dharmawan $^{2}$ \\ ${ }^{1}$ Department of Electrical Engineering, Faculty of Scince and Technology, Universitas Respati Yogyakarta \\ JL. Laksda Adisucipto KM 6,3 Depok Sleman Yogyakarta 55281, Indonesia \\ ${ }^{2}$ Department of Electrical Engineering, Faculty of Engineering, Universitas Muhammadiyah Yogyakarta \\ Jalan Brawijaya, Geblangan, Tamantirto, Kasihan, Yogyakarta 55183, Indonesia
}

*Corresponding author, e-mail: listyalina@ respati.ac.id

\begin{abstract}
The heart is a vital organ that pumps blood through the blood vessels of the human circulatory system. Hence, performing a periodical cardiac examination is beneficial to assess the heart and cardiovascular condition. In general, cardiac examinations would include several assessments, such as checking blood pressure and recording an ECG. The ECG is a test that measures the electrical activity of the heart beat. The recorded ECG would be used by doctors to determine heart abnormalities. However, performing manual evaluation on the recorded ECG is time-consuming and labor-extensive. To remedy this problem, ait is beneficial to develop a computer assisted diagnosis system for automatic heart diseases detection. Automatic detection can be done via image classification techniques that would generally take segmented ECG images as the input. In this study, ECG image segmentation is carried out through several stages, such as gray scaling, contrast enhancement, and segmentation. The results of this study suggest that they can be further used as the input of automatic detection of heart disease.
\end{abstract}

Keywords: Electrocardiography, Heart Dieseases, Images, Segmentation

\section{Introduction}

Heart diseases are the leading cause of mortalities. Nowadays, not only elderly people are at a risk of heart diseases, teenagers and children also have a risk of heart diseases. To reduce the risk of death from heart diseases, performing cardiac examinations is crucial. One of many aspects assessed during the examinations is the heart abnormality recorded using the Electrocardiograph (ECG) [1].

The ECG recorded during the cardiac examination would be analyzed by doctors to determine the heart condition. However, manual evaluation and analysis are labor-extensive and would render a high amount of time. In this respect, automatically analyzing the heart's electrical signals on the ECG using a computer program is desirable.
Such computer programs typically use the concept of artifical intelegence in analyzing the heart condition and subsequently detecting the abnormalities.

The computer program for automatic heart diseases detection would generally takes the ECG images as the input. These images are subsequently processed using several image processing techniques such as grayscalling, contrast enhancement and segmentation. The performance of the program would then rely on the quality of the results of the image processing techniques.

This research aims to propose a segmentation method for ECG images. The proposed method consists of several image processing techniques such as grayscalling, contrast enhancement and thresholding. Grayscalling is beneficial to reduce the computational complexity of the proposed method while contrast enhancement plays a vital 
role in improving the contrast of the ECG images. Finally, the thresholding step aims to provide the binary maps for the ECG images.

We organize the remaining section of this paper as follows. Section 2 presents the theoretical basis of this research. In Section 3, we describe the detail of our research methodology. We present and discuss the experimental results in Section 4. Finally, we draw a concluding remark in Section 5.

\section{Theoretical Basis}

\section{II.1. Heart}

The heart is a hollow organ that has four compartments, namely the right atrium, left atrium, right ventricle and left ventricle. The heart is located between the two lungs in the middle of the thoracic cavity. Two-thirds of the heart is located at the left of the midstrenal line [4]. The anatomy of the heart is illustrated in Fig. 1.

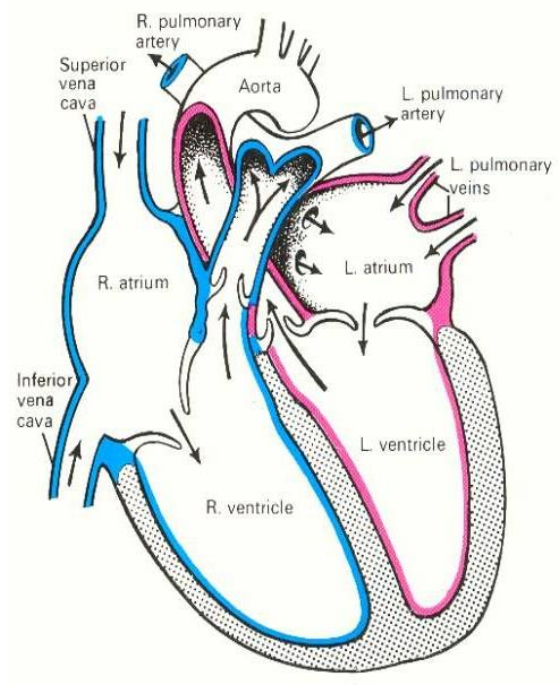

Fig. 1. The heart anatomy [4]

An abnormality in the heart is a condition that causes the heart can't work as it should. Usually this disorder occurs in the heart muscles vasculars. There are many kinds abnormalities in the heart are generally detected throuh the heart beat. In general, there are three conditions in regard to the heart beat rate. The first condition is the normal rhythmic sinus, a condition where the heart regularly beats at 60-100 beats per minute. Secondly, the sinus tachycardia is a condition where the heart beats at a rate of more than 100 beats per minute. Finally, the sine bradycardia is a condition where the heart beats less than 60 beats per minute [5].

\section{II.2. Electrocardiography (ECG)}

Electrocardiograph (ECG) is a signal recording device that records the cardiac electricity signal. The development of this tool began when Augustus Waller take a systematic measurement to the heart with an electricity point of view. In his experiment, Augustus Waller used the Lippman capillary electrometer mounted on a projector. This discovery inspired the development by a Dutch doctor William Eithoven, who replace the Lippman capillary electrometer with the Galvanometer string that provides a more sensitive measurement [6]. An example of ECG devices used nowadays is depicted in Fig. 2.

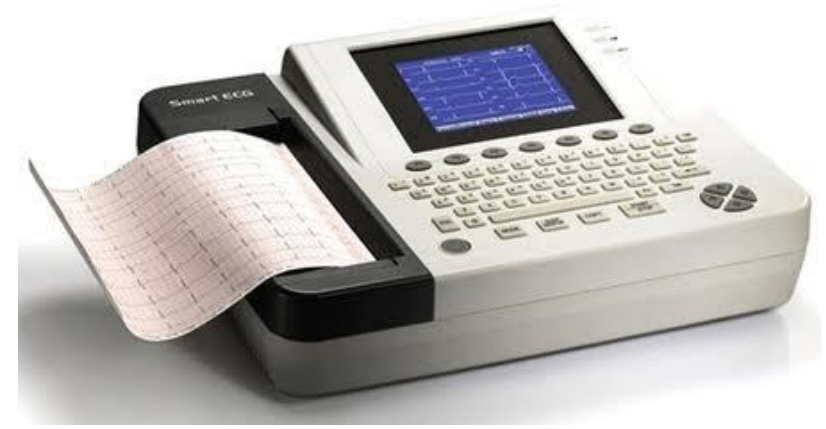

Fig. 2. An example of ECG devices

For the evaluation and analysis purposes, the recorded electropotential of the heart using the ECG would generally be displayed in the monitor or rinted in a piece of paper. An example of the ECG signal printed in a piece of paper is provided in Fig. 3.

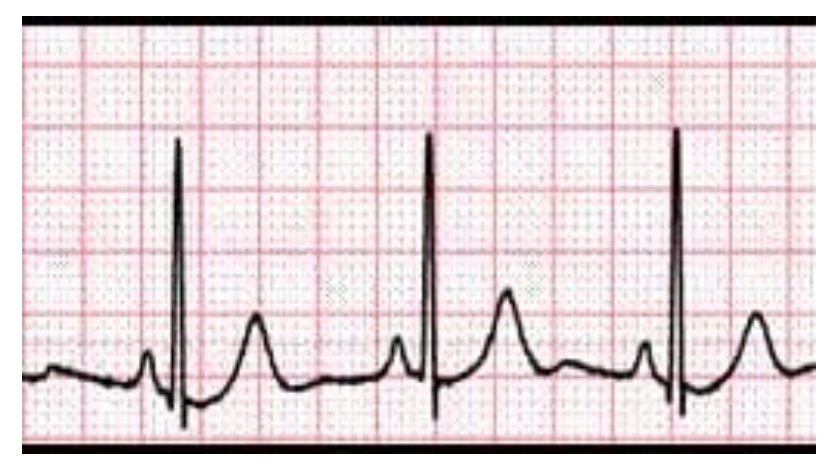

Fig. 3. An example of ECG recording results

\section{II.3. Image Processing}

In the mathematical point of view, an image is a continuous function of the light intensity in a two dimensional plane. The image can also be interpreted as a collection of pixels arranged in a two-dimensional array. Each pixel of an image will have a value in certain range and it defines a 
measure of the intensity of light at that point [8]. In general, for a color and grayscale image, the pixel value will range from 0 to 255. Fig. 4 shows a color image and its respective grayscale map.

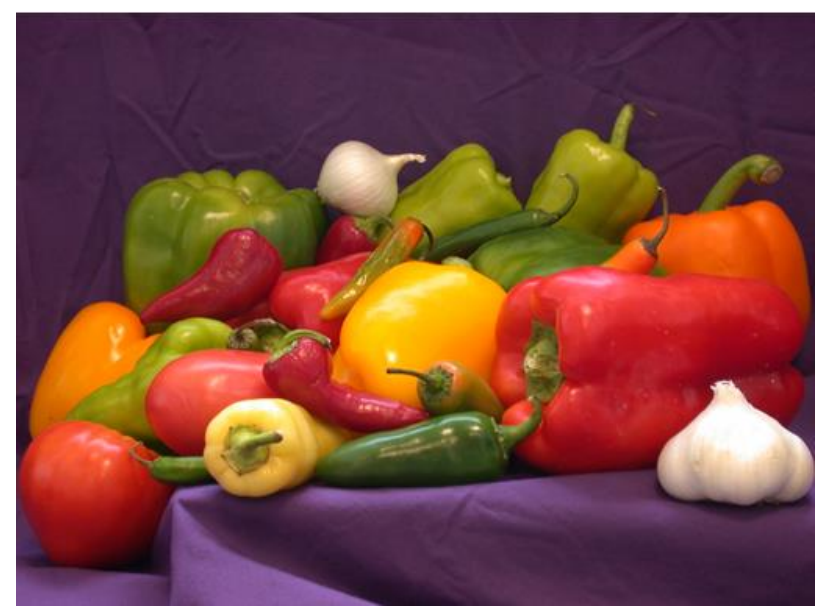

(a)

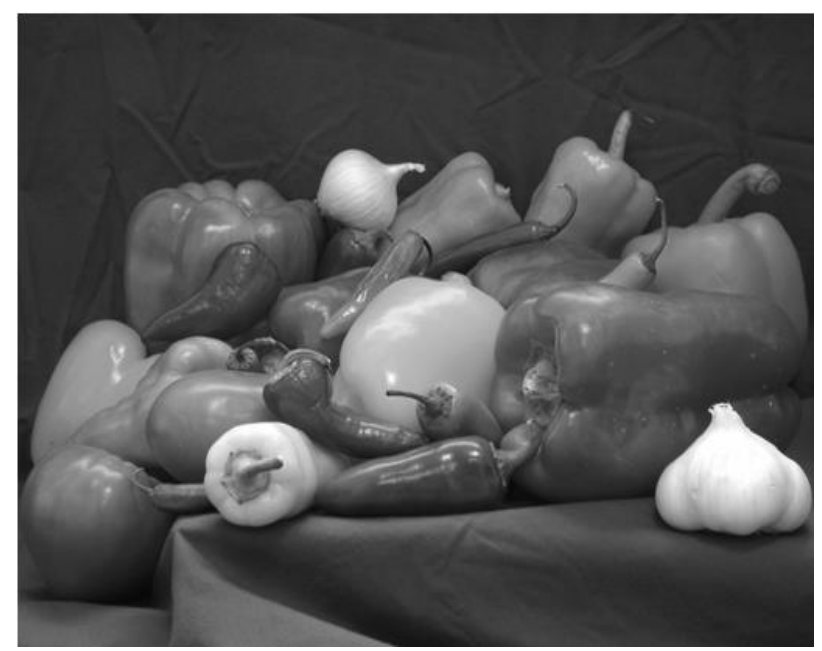

(b)

Fig. 4. (a) A color image and (b) its respective grayscale map

A digital image as shown in Fig. 4 can be represented in the form of a matrix $\mathrm{H} \times \mathrm{W}$, where $\mathrm{H}$ and $\mathrm{W}$ denote the height and width of the image, respectively. The origin point of the image coordinate system is located in the upper left-hand corner while that of the cartesian coordinate system is located in the lower left corner [9].

Besides the color and grayscale image, there exists another type of images called a binary image. A binary image is a type of images whose the pixel values range only 0 and 1 . The process to obtain a binary image from a color or grayscale image is called segmentation. In another word, segmentation is the process of partitioning images into several regions or objects. There exists several methods to perform image segmentation where the simplest method is through applying a threshold value to the color or grayscale image. This process is commonly called as thresholding and can be expressed as follows:

$$
g(x, y)=\left\{\begin{array}{c}
1, f(x, y) \geq T \\
0, \text { otherwise }
\end{array}\right.
$$

where $g(x, y)$ is a binary map of the grayscale image $f(x, y)$, and $T$ corresponds to the threshold value. The $T$ value plays a crucial role in the thresholding process. The quality of the resulted binary image depends on the used $T$ value [11]. An example of thresholding process on a grayscale image is presented in Fig. 5.

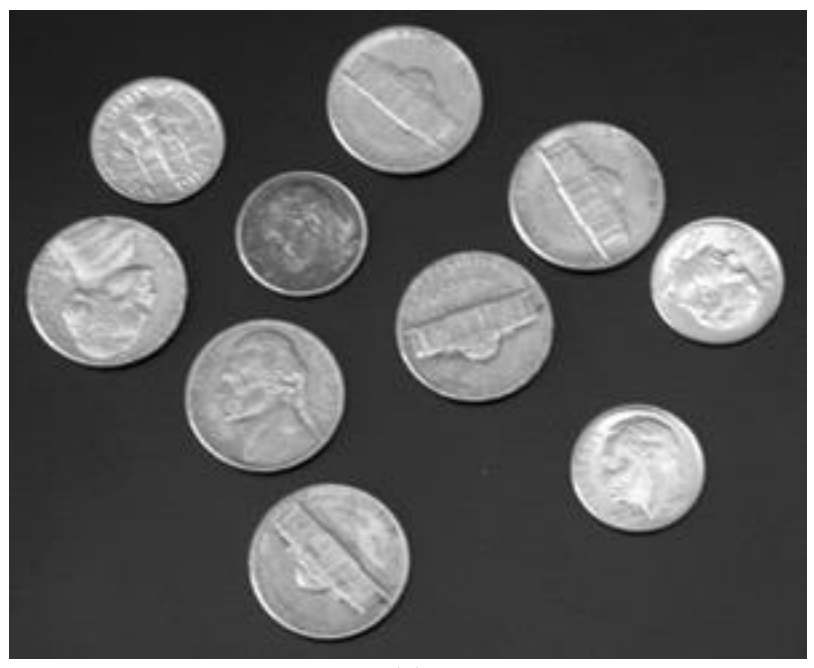

(a)

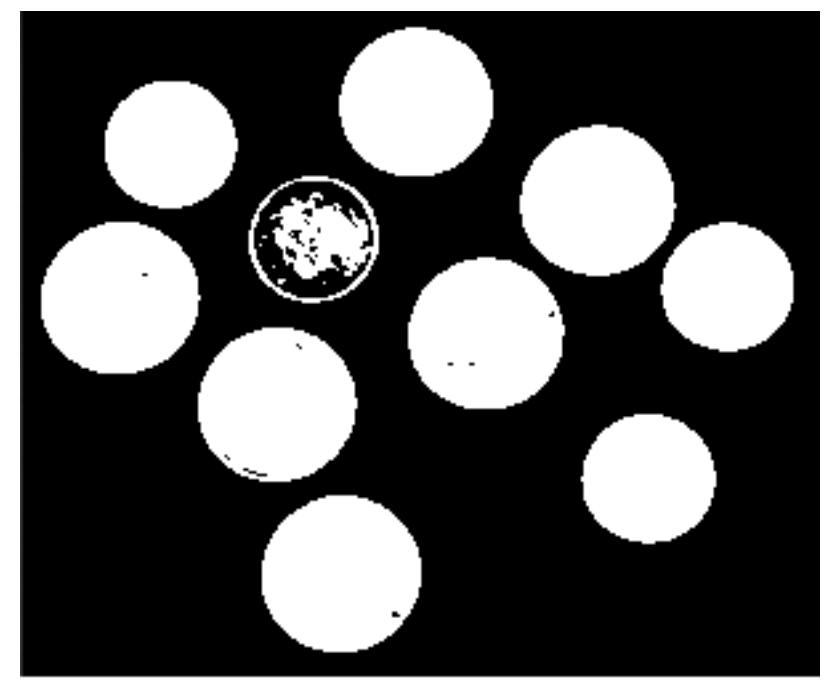

(b)

Fig. 5. (a) An example of grayscale images and (b) its corresponding binary map 


\section{Methodology}

The research procedure is depicted in Fig. 6 and presented as follows.

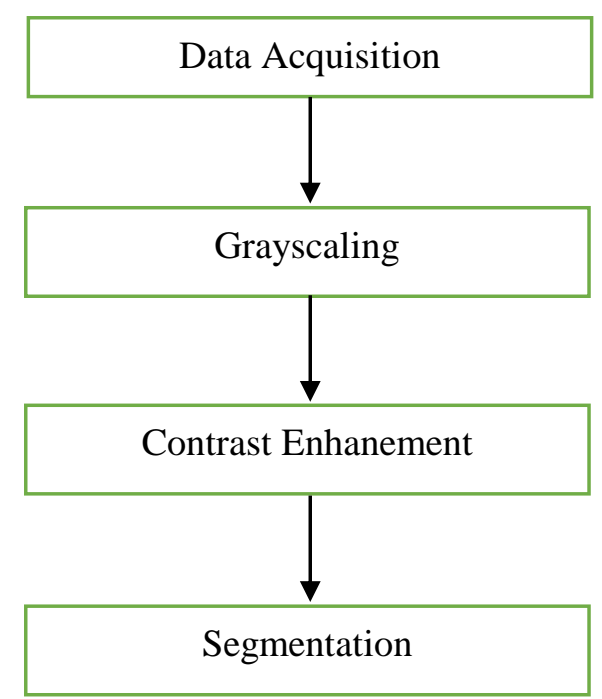

Fig. 6. The steps used to develop our ECG images segmentation method

\section{III.1. Data Acquisition}

To develop the segmentation method, we use primary data of ECG examination results from various patients in the hospital. The data consist of 97 ECG images from normal hearts. The obtained ECG images are then cropped to a certain resolution.

\section{III.2. Grayscaling}

In this step, the color ECG images in the dataset that contain 3 channels of colors are converted into the grayscale images consisting of single color channel. The grayscaling step aims to reduce the computational complexity of the subsequent steps.

\section{III.3. Contrast Enhancement}

Having obtained the grayscale map from the color image, the contrast enhancement step is carried out. In particular, the contrast stretching technique is used to improve the contrast of grayscale ECG images.

\section{III.4. Thresholding}

The segmentation phase aims to obtain the binary map of each ECG image. For this purpose, we use the thresholding technique. In the segmentation result, the pixel of the ECG signal will be considered as the foreground and a value of 1 would be assigned. On the other hand, the remaining pixels would be regarded as the background and would appear as a black pixel (0) in the segmentation result.

The final process in our proposed method is to apply the image morphology techniques, namely the dilation and erosion. The dilation is used to connect several parts of the foreground that are not connected in the segmentation results while the erosion is employed to maintain the original thickness of the ECG pattern.

\section{Results and Discussion}

In this section we will present and discuss the results of our algorithm. Fig. 7 shows the examples of the input and output of the grayscaling step. In the figure, we can observe that the grayscale image in Fig. 7 (b) has only a single channel, making the subsequent process can be done with a lower computational complexity.

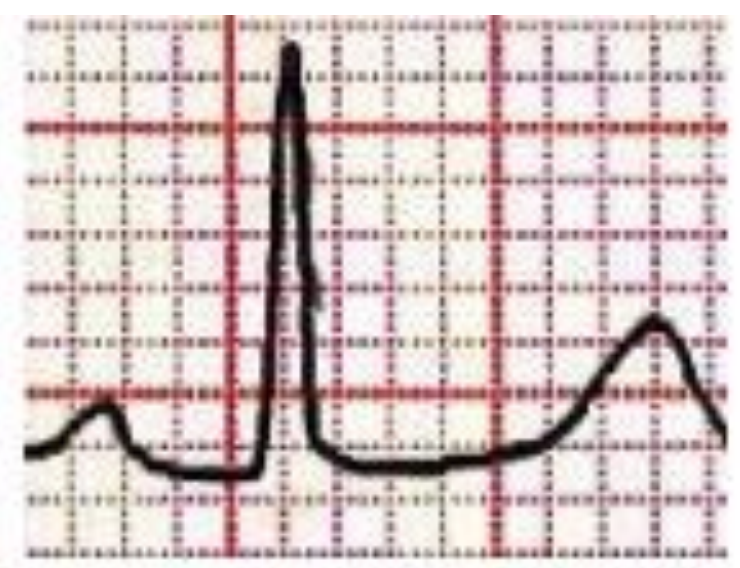

(a)

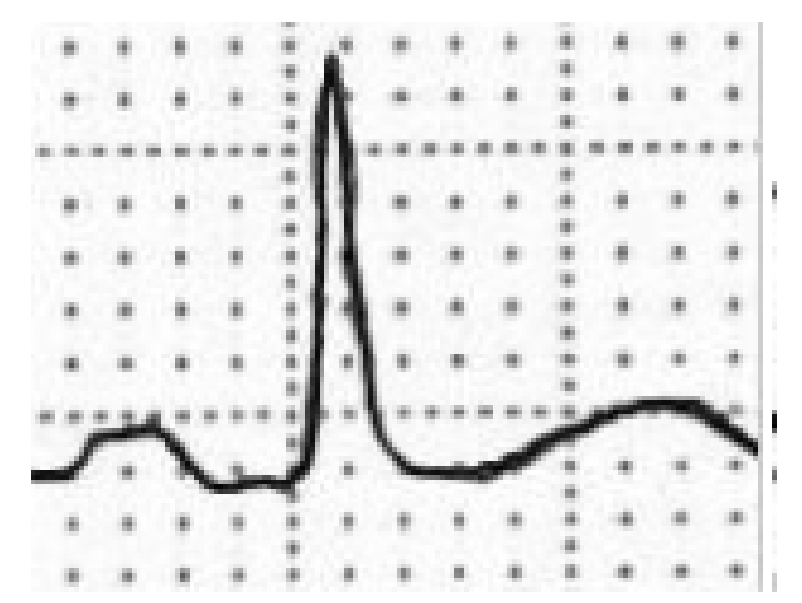

(b)

Fig. 7. (a) The color ECG image and (b) the grayscale ECG image 
The grayscale ECG images becomes the input of the contrast enhancement step as illustrated in Fig. 8. In the figure, we may observe that the contrast stretching technique successfully improves the contrast of the grayscale image, making the ECG pattern can be easily distiguished from the background. Hence, the thresholding step can be further done effectively.

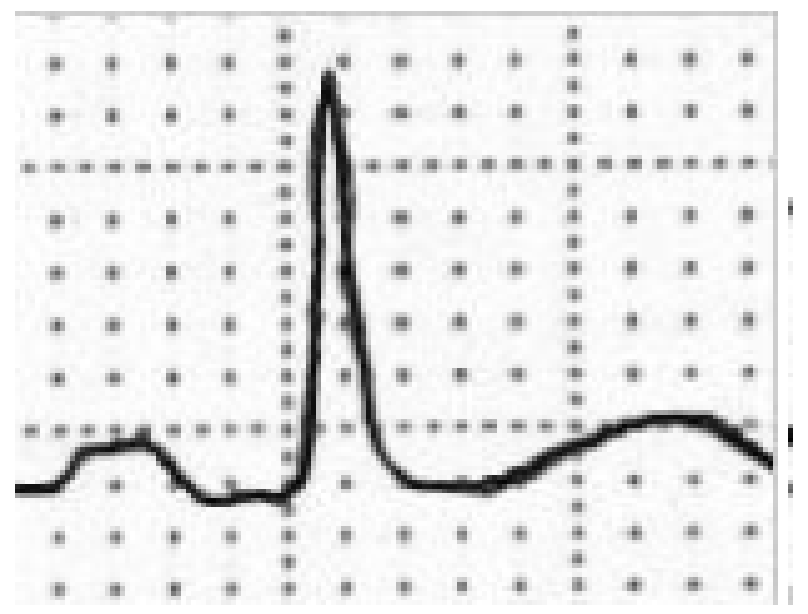

(a)

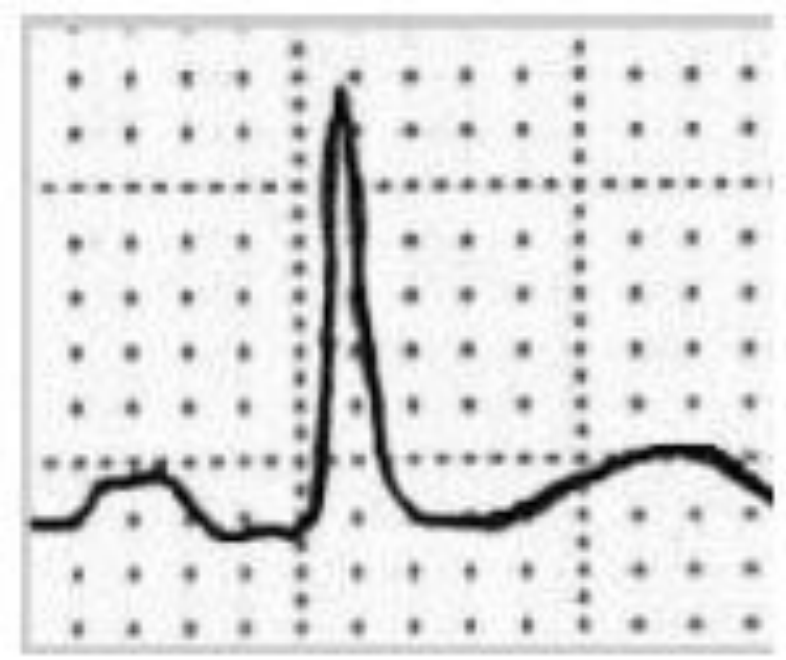

(b)

Fig. 8. (a) The grayscale ECG image and (b) the result of the contrast enhacement step

The output image of the contrast enhancement step is then segmented to distinguish the ECG pattern from the background. This segmentation is done by providing a certain threshold value such that the intensity value located above the threshold value is grouped into white (1) pixel and that located below the threshold value is grouped into black pixel (0) or vice versa. An example of the thresholding result is provided in Fig. 9. As can be observed in the figure, the thresholding process has effectively provided the binary map for the ECG image where the ECG pattern and the background appear in white (1) and black (0) pixels, respectively. However, it is also observed in Fig. 9 that there exist several discontinuities at several pixels in the binary map.

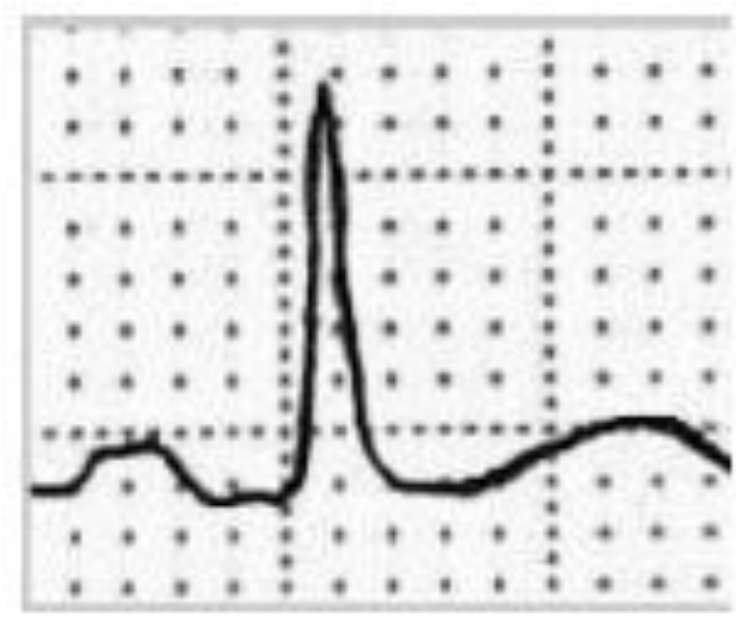

(a)

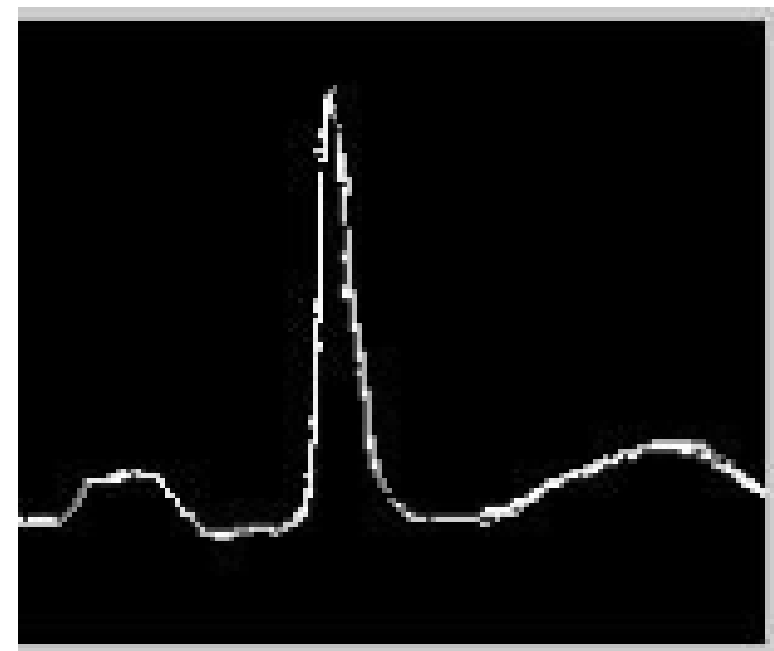

(b)

Fig. 9.The (a) input and (b) output of the thresholding step

In the final step of our segmentation method, the binary map of the ECG image is refined partly to remove the discontinuity at several pixels as shown in Fig. 9. To connect the broken lines due to the thresholding process, two basic morphological operations are done on the binary image. In particular, the dilation and erosion operations are performed to connect images interrupted during the segmentation process and to maintain the original thickness of the ECG pattern, respectively. An 
example of the refined binary map is depicted in Fig. 10.

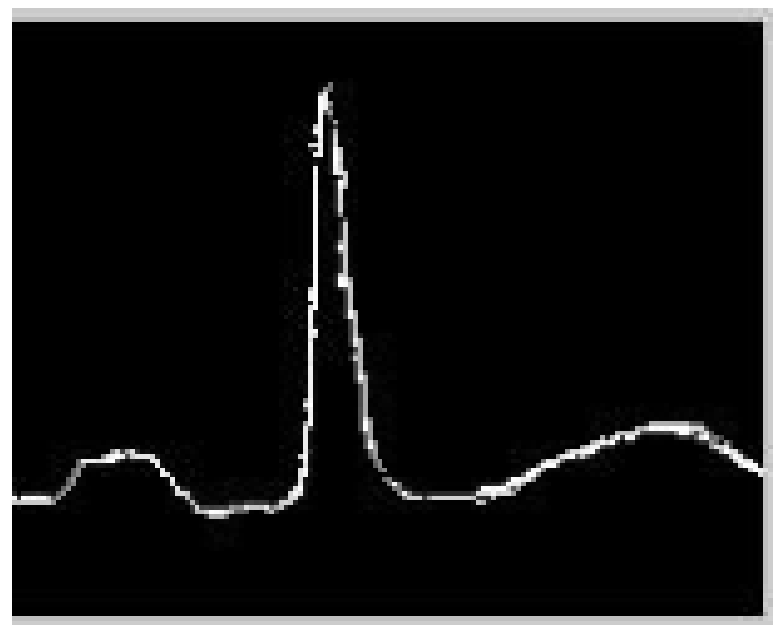

(a)

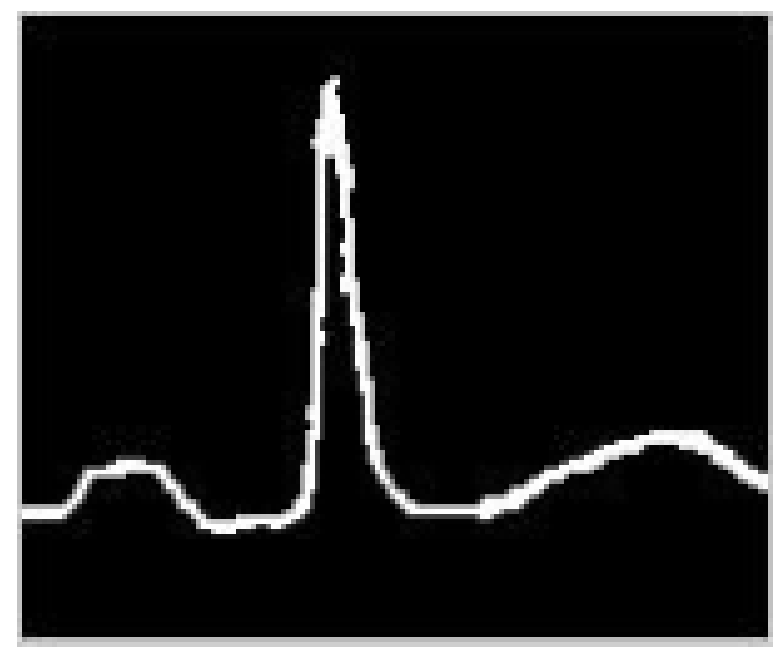

(b)

Fig. 10. (a) The result of the thresholding step and (b) the final binary map of the ECG image

\section{Conclusion}

In this paper, we have proposed an ECG image segmentation method. In the proposed method, several steps such as grayscalling, contrast enhancement and segmentation have been used. Grayscalling is beneficial to reduce the computational complexity of the proposed method while contrast enhancement plays a vital role in improving the contrast of the ECG images. Finally, the thresholding step aims to provide the binary maps for the ECG images

\section{References}

[1] Dr, Soeparman. 1987. Ilmu Penyakit Dalam Jilid I Edisi Kedua. Jakarta: Balai Penerbit FKUI.

[2] Endarko, et al. 2006. Aplikasi Pengolahan Citra Elektrokardiograf dan Jaringan Saraf Tiruan untuk Identifikasi Penyakit Jantung Koroner. Jurnal Fisika dan Aplikasinya. Surabaya.

[3] Kusumadewi, Sri. 2003. Artificial Intelegence (Teknik dan Aplikasinya). Graha Ilmu. Jogjakarta.

[4] Guyton, A. C. 1995. Fisiologi Manusia dan Mekanisme Penyakit, Alih bahasa: Petrus Andrianto, Penerbit Buku Kedokteran. EGC, Jakarta.

[5] Marieb, Elaine. 1994. Human Anatomy and Physiology. San Francisco, CA: Pearson Education.

[6] Berbari, E. J. 2000. Principle of Electrocardiography. The Biomedical Enginering Handbook. CRC Press LCC.

[7] Cromwell, Leslie cs. 1980. Biomedical Instrumentation and Measurments. Prentice Hall.

[8] Low, A.,. 1991. Introduction Computer Vision and Image Processing, Mc Graw Hill Book Company, London.

[9] Mabrur, S. Si, Andik. 2011. Pengolahan Citra Digital Menggunakan Matlab. Tulungagung.

[10] Munir, Rinaldi. 2004. Pengolahan Citra Digital dengan Pendekatan Algoritmik. Informatika Bandung. Bandung.

[11]Nurdin, Dewi Triwulandari. 2010. Konsep Pengolahan Citra Digital dan Ekstrasi fitur. Graha Ilmu. Jogjakarta.

\section{Authors' information}

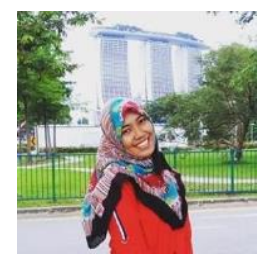

Latifah Listyalina is a lecturer at the Department of Electrical Engineering, Faculty of Science and Technology, Universitas Respati Yogyakarta. She received the B.Eng degree in Biomedical Engineering from Universitas Airlangga, Indonesia, in 2013 and the M.Eng. degree in Electrical Engineering from Universitas Gadjah Mada, Indonesia in 2016. Her research interests include biomedical signal and image processing, computer vision and pattern recognition.

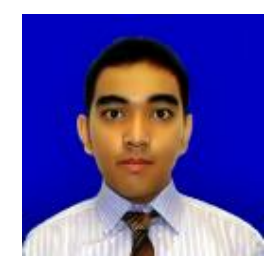

Dhimas Arief Dharmawan is a lecturer at the Department of Electrical Engineering, Faculty of Engineering, Universitas Muhammadiyah Yogyakarta. $\mathrm{He}$ received the B.Eng. degree in Electrical Engineering from Universitas Gadjah Mada, Yogyakarta, Indonesia in 2014. He is currently pursuing the Ph.D. degree in Electrical Engineering at Nanyang Technological University (NTU), Singapore. His research interests include image filtering and segmentation, machine learning, computer vision and pattern recognition. 